\title{
Clinico-Histopathological Consistency in Dermatological Diseases
}

\author{
*Mahmud $\mathrm{MM}^{1}$, Mamun MAA ${ }^{2}$, Hazra $\mathrm{SC}^{3}$, Habib RB ${ }^{4}$, Chowdhury MMH${ }^{5}$.
}

\begin{abstract}
Skin biopsy for histopathology is the most reliable investigation for diagnosis of skin diseases. The main purpose of skin biopsy is to confirm clinical diagnosis but dermatologists usually looking for the concordance with histopathological report. The aim of the study was to observe the consistency of clinical and histopathological diagnosis of skin diseases. An observational study was conducted on 630 patients that undertaken skin biopsy and that was performed at the Department of Dermatology and Venereology, Bangabandhu Sheikh Mujib Medical University from January 2018 to January 2019. Patients who were advised for biopsy by outpatient and inpatient department and the biopsy was done accordingly was included in the study. Finally the inclusion was confirmed when the histopathological report was available. Demographic information, clinical diagnosis, type of biopsy procedure, types of specimen taken and send for histopathological procedure and the histopathological diagnosis was noted in data collection sheet. Histopathological diagnosis and its correlation with clinical diagnosis was assessed for consistency and it was the main outcome measure of the study. The mean age of patients on whom biopsy was performed was $35.14 \pm 16.57$ years and the age range was 5-82 years. Male patients outnumbered female and the male to female ratio was 1.15: 1 . Three types of biopsy were performed among them incisional biopsy was the commonest type (93.5\%). In most of the cases
\end{abstract}

1. *Dr. Md. Mostaque Mahmud, Assistant Professor, Department of Dermatology and Venereology, Bangabandhu Sheikh Mujib Medical University (BSMMU), Dhaka. Email: drmstq@yahoo.com

2. Dr. Md. Abdullah-Al Mamun, Medical Officer, Department of Dermatology and Venereology, BSMMU, Dhaka.

3. Dr. Samaresh Chandra Hazra, Assistant Professor, Department of Dermatology and Venereology, Dhaka Medical College, Dhaka.

4. Dr. Rahat Bin Habib, Assistant Professor, Department of Pediatrics, Shaheed Syed Nazrul Islam Medical College, Kishoreganj.

5. Dr. Md. Mostaque Hassan Chowdhury, Associate Professor, Department of Dermatology, Kushtia Medical College, Kushtia.

${ }^{*}$ For correspondence collected specimen was skin $94.76 \%$, others type of specimens were mucous membrane $2.6 \%$, nail matrix $1.9 \%$ and $0.6 \%$ specimen was hair follicle. Among the cases $71.43 \%$ was diagnosed clinically. The common clinical diagnosis in which biopsy was done was psoriasis and its types $17.77 \%$, lichen planus and its variants $14.12 \%$, the connective tissue diseases $6.19 \%$ and infectious diseases $5.39 \%$. In $79.52 \%$ cases histopathological diagnosis was done and $68.22 \%$ diagnosis was consistent with the clinical diagnosis. The maximum clinico-pathological concordance was found in vesiculo-bullous disease $93.33 \%$. Then connective tissue diseases $79.48 \%$, vasculitides $75 \%$ and lichenoid diseases $73.56 \%$. Skin biopsy is a conclusive tool to overcome diagnostic dilemmas in dermatological diseases. The clinico-pathological concordance is assumed lower than the expectation of dermatologists but the collective efforts of dermatologists and pathologists can improve the capacity of diagnosis of biopsy samples.

Keywords: Skin biopsy, histopathological diagnosis, clinicohistopathological consistency,

\section{INTRODUCTION}

In dermatology skin biopsy is a valuable surgical procedure. It plays a deciding role in dermatological practice when it needs to confirm the clinical diagnosis, exclusion of multiple differential diagnosis and when there is no responses of treatment. Though it is an invasive surgical procedure a well-equipped operation theatre required to perform that procedure. The aim of this biopsy procedure is to collect specimen for routine histopathology, immunohistochemistry, direct immunofluroscent test (DIF), PCR test and electron microscopy. ${ }^{1}$ Skin, nail matrix, mucous membrane and hair follicle are the target specimen that are usually collected in dermatology operation theatre (OT). Various methods and types of skin biopsy are practiced according to the lesions and site of diseases. Skin biopsy and histopathology is a time consuming procedure and somewhat inconvenient to the patients because it needs at least 3 working days in histopathology department to get a report and another visit will require at least 7 days to stitch off the biopsy site. ${ }^{2}$ The pre-biopsy evaluation includes history of any hypersensitivity to local anesthetics, any history of needle 
phobia, review of any bleeding disorders, recent use of any anticoagulant and history of any bleeding tendency. Site selection for biopsy is the first step at operation theatre followed by skin sterilization and injection of local anesthesia. ${ }^{3}$ After thoroughly wash the area with chlorhexidine or povidone iodine or alcohol swab the xylocaine $1-2 \%$ solution is injected to make the site painless. In some occasions epinephrine (1:100000) is used as an additive for reducing the bleeding at operational site and sodium bicarbonate $(8.4 \%)$ can add to increase $\mathrm{pH}$ and reducing pain. 4,5 The precaution is needed to control adverse effects like hypersensitivity of anesthetic, pain, bleeding, infections and scarring. Various type of skin and soft tissue biopsy are practiced in dermatology incisional, excisional, punch, shave and curettage techniques are applied as per need. ${ }^{6}$ Collected specimen by biopsy is sent for histopathology with appropriate preservative and well labelled container. Formalin is usually used as fixative for routine histopathology specimen, normal saline is used for DIF and Michael's medium is rarely used for long distance transport. ${ }^{7}$ Boyd AS et al. had proposed 5 categories of information while sending the specimen to dermatopathologists all of that beginning with the letter 'D'. The 5 Ds included description of specimen, demographics, duration, diameter, and diagnosis. They hoped that the inclusion of this information will assist in their accurate interpretation. ${ }^{8}$

\section{MATERIALS AND METHODS}

The study was conducted on 630 patients who were advised for skin biopsy and was performed that accordingly at the department of Dermatology \& Venereology or with referred from other department Bangabandhu Sheikh Mujib Medical University, Dhaka, Bangladesh. The duration of that observational study was from January 2018 to January 2019 with included all the cases to whom biopsy was performed and histopathological report were found. Age of patients, sex, clinical diagnosis, type of biopsy done, type of specimen collected and advised for histopathological process was observed and documented in a data collection sheet. In case of clinical diagnosis where only description of lesion was found was grouped as 'not diagnosed clinically'. In case of multiple differential diagnosis the first was taken as 'clinical diagnosis' for descriptive analysis but it was defined as 'consistent' with histopathological diagnosis when any one of the differential diagnosis was matched. The cases were excluded from the study if there any incomplete demographic, clinical, procedural information and lacked of histopathological report.

\section{RESULTS:}

After skin biopsy was done according to instruction 630 patients was traced with histopathological report

Table I Shows incisional biopsy was performed on maximum patients (93.5\%). Fewer of them was selected for punch and excisional biopsy.

Table I: Distribution of patients according to the types of biopsy

\begin{tabular}{|l|c|c|}
\hline Type of biopsy & Frequency & Percent \\
\hline Punch & 21 & 3.3 \\
\hline Incisional & 589 & 93.5 \\
\hline Excisional & 20 & 3.2 \\
\hline
\end{tabular}

Table II Shows the most common specimen was taken by biopsy was skin (94.76\%). Nail matrix, hair follicle and mucous membrane was the other types of specimen that was collected for histopathology.

Table II: Types of specimen was taken for histopathology:

\begin{tabular}{|l|c|c|}
\hline Specimen & Number & Percent \\
\hline Skin & 597 & 94.76 \\
\hline Nail matrix & 12 & 1.90 \\
\hline Hair follicle & 4 & 0.60 \\
\hline Mucous membrane & 17 & 2.60 \\
\hline
\end{tabular}

Table III Shows all the specimen collected by biopsy was sent for routine histopathological processing ( $\mathrm{H} \& \mathrm{E}$ staining) and fewer of them were sent for DIF (1.74\%) and immunohistochemistry $(0.31 \%)$ test along with routine test.

Table III: Distribution of patients according to types of histopathological test

\begin{tabular}{|l|c|c|}
\hline Type of histopathological test & Frequency & Percent \\
\hline Routine histopathology (H\&E) & 630 & 100 \\
\hline Direct immunofluroscent test (DIF) & 11 & 1.74 \\
\hline Immunohistochemistry (IC) & 2 & 0.31 \\
\hline
\end{tabular}


Table IV Shows the mean age of patients was 35.14 $( \pm 16.57)$ years. The youngest one was 5 years old and the eldest one was 82 years. Only $14.3 \%$ patients was in pediatric age group (age below 18 years) and $85.7 \%$ was adult and elderly patients. Majority of patients (174) was in the age group 21-30 years and the next major one was $31-40$ years age group (121).

Table IV: Distribution of patients by age

\begin{tabular}{|l|c|c|}
\hline Age group (years) & Frequency & Percentage \\
\hline $0-10$ & 20 & 3.17 \\
\hline $11-20$ & 110 & 17.46 \\
\hline $\mathbf{2 1 - 3 0}$ & $\mathbf{1 7 4}$ & $\mathbf{2 7 . 6 1}$ \\
\hline $31-40$ & 121 & 19.20 \\
\hline $41-50$ & 87 & 13.80 \\
\hline $51-60$ & 68 & 10.79 \\
\hline $61-70$ & 35 & 5.55 \\
\hline $71-80$ & 14 & 2.22 \\
\hline $81-90$ & 1 & 0.15 \\
\hline Mean age in years & 35.14 & \\
\hline Standard deviation & \pm 16.57 & \\
\hline Age range in years (5 to 82$)$ & 77 & \\
\hline$<18$ years of age & 90 & 14.3 \\
\hline$\geq 18$ years & 540 & 85.7 \\
\hline
\end{tabular}

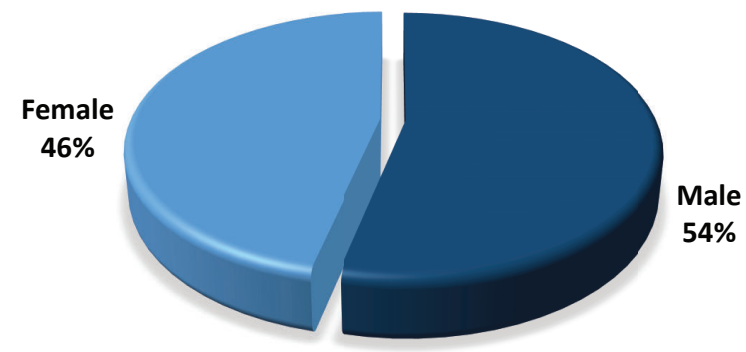

Figure I: Distribution of patients according to sex.

Male patients outnumbered female in that study and that was $338(54 \%)$ and $292(46 \%)$ respectively. The male to female ratio was 1.15: 1 .
Table V Shows four hundred and fifty cases (71.42\%) were diagnosed clinically and grouped as 31 categories and in 180 cases only clinical description were found in spite of diagnosis. Psoriasis was the commonest case that were undertaken biopsy. Lichen planus and variants and the connective tissue diseases were the next common diseases to whom biopsy was done.

Table V: Distribution of cases according to clinical diagnosis

\begin{tabular}{|c|c|c|c|}
\hline \multicolumn{2}{|c|}{ Clinical diagnosis } & \multirow{2}{*}{\begin{tabular}{|c|} 
Frequency \\
112
\end{tabular}} & \multirow{2}{*}{\begin{tabular}{|c} 
Percentage \\
17.77
\end{tabular}} \\
\hline 1. & $\begin{array}{l}\text { Psoriasis: Chronic plaque } \\
\text { and other types }\end{array}$ & & \\
\hline 2. & Lichen planus and variants & 89 & 14.12 \\
\hline 3. & Connective tissue diseases & 39 & 6.19 \\
\hline 4. & Skin infections: & 34 & 5.39 \\
\hline 5. & $\begin{array}{l}\text { Eczema/Dermatitis and } \\
\text { variants }\end{array}$ & 29 & 4.60 \\
\hline 6. & Vasculitides & 24 & 3.80 \\
\hline 7. & Benign tumor/Lesions & 18 & 4.44 \\
\hline 8. & Autoimmune bullous diseases & 15 & 2.38 \\
\hline 9. & Cutaneous malignancy & 15 & 2.38 \\
\hline 10. & Neurocutaneous & 11 & 1.74 \\
\hline 11. & Pityriasis rubra pilaris & 9 & 1.42 \\
\hline 12. & Palmo-plantar keratoses & 8 & 1.26 \\
\hline 13. & Genodermatoses & 8 & 1.26 \\
\hline 14. & Error of metabolism & 6 & 0.95 \\
\hline 15. & Parapsoriasis & 6 & 0.95 \\
\hline 16. & Panniculitis & 4 & 0.63 \\
\hline 17. & Alopecia & 4 & 0.63 \\
\hline 18. & Keratosis pilaris & 3 & 0.47 \\
\hline 19. & Sarcoidosis & 2 & 0.31 \\
\hline 20. & Fixed drug eruption & 2 & 0.31 \\
\hline 21. & Granuloma annulare & 2 & 0.31 \\
\hline 22. & Arsenicosis & 1 & 0.16 \\
\hline 23. & Angiolipoma & 1 & 0.16 \\
\hline 24. & Behcets disease & 1 & 0.16 \\
\hline 25. & Chronic leg ulcer & 1 & 0.16 \\
\hline 26. & Hemangioma & 1 & 0.16 \\
\hline 27. & Lipodermatosclerosis & 1 & 0.16 \\
\hline 28. & Lichen sclerosus & 1 & 0.16 \\
\hline 29. & Oral erosion & 1 & 0.16 \\
\hline 30. & $\begin{array}{l}\text { Progressive pigmentary } \\
\text { dermatoses }\end{array}$ & 1 & 0.16 \\
\hline 31. & Pyogenic granuloma & 1 & 0.16 \\
\hline 32. & Clinically not diagnosed & 180 & 28.57 \\
\hline
\end{tabular}


Table VI Shows out of 630 biopsy specimen clinically and histopathologically diagnosed cases were 450(71.42\%) and $501(79.52 \%)$ respectively. The chi-square statistic was 11.15 and the p-value was 0.0008 significant. With Yates correction chi-square statistic was 10.71 and the p-value was 0.001 which was significant $(<0.05)$.

Table VI: Comparison of clinical and histopathological diagnosis

\begin{tabular}{|l|c|c|c|}
\hline Diagnostic status & Clinically & Histopathologically & P value \\
\hline Diagnosis done & $450(71.42 \%)$ & $501(79.52 \%)$ & $<0.05^{*}$ \\
\hline Description given only & $180(28.57 \%)$ & $129(20.47 \%)$ & \\
\hline
\end{tabular}

${ }^{*}$ p-value obtained from chi-square test and it was significant

Table VII Shows the clinical and pathological diagnosis was most consistent in case of autoimmune bullous diseases (93.33\%). Other diseases with higher clinico-pathological correlation was connective tissue diseases, vasculitides, lichen planus and variants and psoriasis and its types.

Table VII: Top ranked clinico-histopathologically consistent skin diseases

\begin{tabular}{|l|c|c|c|}
\hline Disease group & $\begin{array}{c}\text { Number of Clinically } \\
\text { diagnosed cases }\end{array}$ & $\begin{array}{c}\text { Number of } \\
\text { Histopathologically } \\
\text { diagnosed cases }\end{array}$ & $\begin{array}{c}\text { Percent of clinico- } \\
\text { histopathological } \\
\text { consistency }\end{array}$ \\
\hline Autoimmune bullous disease & 15 & 14 & $93.33 \%$ \\
\hline Connective tissue disease & 39 & 31 & $79.48 \%$ \\
\hline Vasculitides & 24 & 18 & $75.00 \%$ \\
\hline Lichenoid disease & 87 & 64 & $73.56 \%$ \\
\hline Psoriasis and types & 112 & 79 & $70.53 \%$ \\
\hline
\end{tabular}

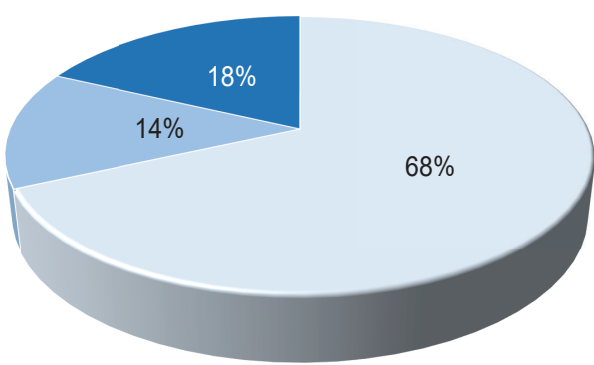

$\square$ Clinico histopathological concordance $\square$ Non-cordance $\square$ Non-diagnosed

Figure II: Clinical and histopathological concordance in biopsy specimen

Four hundred and fifty cases were clinically diagnosed out of them Clinical and histopathological consistency was found in 307(68.22\%) cases. Histopathologically diagnosed but non-consistent with clinical diagnosis was in $14 \%$ cases and no diagnosis was done histopathologically in $18 \%$ cases.

\section{DISCUSSION}

In dermatological practice skin biopsy is the most reliable procedure of diagnosis worldwide. To conclude in a diagnosis from multiple differential diagnoses or when there is no response with usual treatment and some occasion for research purpose skin biopsy is advised. In our study duration on an average 780 patients were attended at outpatient department of dermatology daily and only around 7 skin biopsy was performed per day the percentage was $0.08 \%$. That figure proves the great efficiency of our dermatologists as they manage more than $99 \%$ of skin cases with clinical diagnosis. The mean age of patients to whom biopsy was performed was $35.14 \pm 16.57$ years. Mode was 30 years and median was 32 years. Minimum age of patient was 5 and the maximum age was 82 years. Among them $14.3 \%$ was pediatric age group and the rest of them $(85.7 \%)$ was adult. The majority of the patients $(27.61 \%)$ was in 21-30 years age group. In a similar study regarding skin biopsy the mean age of 
patients was $54.58 \pm 0.26$ and the median 57 years. ${ }^{9}$ The patients of that study were more elderly than our patients. Regarding gender issue the difference was not so wide but male outnumbered the female. There were $54 \%$ cases were male and $46 \%$ were female and male to female ratio was 1.15: 1. Corfitis et al. found that in their study on 5941 patients $48.2 \%$ were males and $51.8 \%$ Females therefore female outnumbered the male. That findings was not similar with us. Another similar study in performed in India showed that their male to female ratio was 1.16: 1 and majority (36\%) of patients undertaken skin biopsy was in 16-30 years of age group. ${ }^{10}$ Their findings were similar to us. There were three types of biopsy was done the majority of them were incisional biopsy (93.5\%). Excisional biopsy was done on $3.2 \%$ cases when the diagnosis was the changing mole, Basal cell carcinoma and pyogenic granuloma. Punch biopsy was done on 3.3\% cases majority was in mucous membrane involvement. In a similar retrospective study on 403 patients the investigators had conducted $73 \%$ incisional biopsy, $7.7 \%$ excisional biopsy and $19.4 \%$ punch biopsies on skin. ${ }^{11}$ they had performed incisional biopsy as in majority of cases like our study. Single or multiple differential clinical diagnosis was found in $71.42 \%$ cases and the clinical description was found in rest of the (28.57\%). Total 95 different types and sub types of diagnosis was recorded. They were classified as 32 grouped and ungrouped categories for analysis. The most common cases to whom biopsy was done was psoriasis and its sub types. A total 112 $(17.77 \%)$ cases was of psoriasis category. The next common cases were lichen planus and its variants 89 (14.12\%), Connective tissue diseases 39 (6.19\%), infectious diseases 34 (5.39\%), eczematous or dermatitis $29(4.6 \%)$ and vasculitides 24 (3.8\%). Malik et al. in a study on 2216 biopsies had shown that their common clinical diagnosis were leprosy (18\%), lichenoid diseases $(14.57 \%)$, psoriasis and types (6.85\%) and eczema or dermatitis were $3 \%$ of all dermatoses. ${ }^{10}$ Another study conducted in Greece with 6816 patients of biopsy they found that the common clinical diagnosis were the cutaneous malignancy (19.28\%), papulosquamous diseases (12.13\%), nevi (10.51\%), dermatitis (8.4\%) and the miscellaneous diseases was $22.49 \%$ of total dermatoses. ${ }^{9}$ that two study had some similarity and some dissimilarity with our study. In a study of Greece malignant skin diseases are the commonest case for biopsy because of their white skin on the other hand in India leprosy is still a major burden of skin diseases but in our community psoriasis and psoriasiform skin lesions are the main concern for biopsy. Question might be raised why psoriasis was at the top of the list though it is a common and easily diagnosable disease? It could be due to treatment failure, relapse, flare and research purpose. The clinical diagnosis were found in $71.42 \%$ cases and that was confirmed by histopathological reports. In total $79.52 \%$ cases conclusive histopathological diagnosis was done and in $20.48 \%$ cases there was only description was found. That difference was significant statistically (p-value $<0.05 \%)$. In $68.22 \%$ cases the histopathological diagnosis was consistent with clinical diagnosis. The clinicpathological concordance was found $68 \%$ by Korfitis et al., $71 \%$ by Venugopal et al. and $76.8 \%$ was found by Aslan et al. in different but similarly designed studies. Their findings were nearer to our study. ${ }^{9,10,11}$ The clinicohistopathological consistency was higher in studies conducted by Yap et al. and Gupta et al. they found the correlation were $86.8 \%$ and $85.8 \%$ respectively. ${ }^{12,13}$, The consistency rate was found lower than our findings in the studies of Malik et al. (61.01\%) and by Balasubramanium et al. $(59.80 \%) .{ }^{14,15}$ The consistency rate was highest in where the pathologists had made the report with consulting the dermatologists who were responsible with the case. In current study the clinico-histopathological consistency was highest in autoimmune bullous disease (93.33\%). The next higher consistency was found in Connective tissue diseases (79.48\%), Vasculitides (75\%), Lichen planus (73.56\%) and Psoriasis (70.53\%). In a similar study the clinico-pathological correlation was highest in Genodermatoses (100\%). The next common consistent cases were autoimmune bullous diseases (79.01\%), environmental dermatoses (73.3\%) and the inflammatory dermatoses (72\%). George et al. found the clinico-pathological correlation $100 \%$ in leprosy, $90.3 \%$ in morphea, $85.3 \%$ in psoriasis and $82.7 \%$ in vesiculobullous diseases in a study on 800 cases. ${ }^{16}$ The rate of correlation is different in various study cause might be the wide variety of dermatological diseases and lot of factors involved in country to country.

\section{CONCLUSIONS}

Skin biopsy is an invasive procedure to diagnosis of clinically unsettled cases of dermatology. In dermatological perspective clinico-pathological consistency is needed to take decision for patient management. But the rate of concordance is lower than expectation. A coordinated and collaborative effort of dermatologists and the pathologists could improve the rate of diagnostic consistency. A large scale, multi-centric and long duration study would be more conclusive in that regards. 


\section{REFERENCES}

1. Nischal U, Nischal KC, Khopkar U. Techniques of skin biopsy and practical considerations. Journal of cutaneous and aesthetic surgery. 2008 Jul; 1(2):107.

2. Ramsey ML, Rostami S. Skin biopsy. StatPearls [Internet]. 2020 Jan 7.

3. Yang S, Kampp J. Common Dermatologic Procedures. Med Clin North Am. 2015 Nov; 99(6): 1305-21.

4. Sharma KS, Lim P, Brotherston MT. Excision versus incision biopsy in the management of malignant melanoma. J Dermatolog Treat. 2016; 27(1):88-90.

5. McKay W, Morris R, Mushlin P. Sodium bicarbonate attenuates pain on skin infiltration with lidocaine, with or without epinephrine. Anesth Analg. 1987 Jun; 66(6):572-4.

6. Cheng R, Bialas RW, Chiu ST, Lawrence TJ, Lesesky EB. Punch biopsy vs. shave biopsy: a comparison of margin status of clinically atypical pigmented lesions. Br J Dermatol. 2015 Sep; 173(3):849-51.

7. Elston DM, Stratman EJ, Miller SJ. Skin biopsy: Biopsy issues in specific diseases. J Am Acad Dermatol. 2016 Jan; 74(1):1-16; quiz 17-8.

8. Boyd AS, Neldner K. How to submit specimen for cutaneous pathology analysis. Arch Fam Med. 1997; 6(64-66):54.

9. Korfitis C, Gregoriou S, Antoniou C, Katsambas AD, Rigopoulos D. Skin biopsy in the context of dermatological diagnosis: a retrospective cohort study. Dermatology research and practice. 2014 Jan 1; 2014.
10. Venugopal R, Shankar P, Pathania V. Clinicopathological correlation in the diagnosis of skin diseases: A retrospective study. Medical Journal of Dr. DY Patil Vidyapeeth. 2020 Nov 1;13(6):648.

11. Aslan C, Göktay F, Mansur AT, Aydıngöz İE, Güneş P, Ekmekçi TR: Clinicopathological consistency in skin disorders: a retrospective study of 3949 pathological reports. J Am Acad Dermatol. 2012, 66:393-400.

12. Yap B, Boon F: Dermatopathology of 400 skin biopsies from Sarawak. Indian J Dermatol Venereol Leprol. 2009, 75:518-519

13. Gupta P, Karuna V, Grover K, Rathi M, Verma N. The histopathological spectrum of skin diseases with emphasis on clinicopathological correlation: A prospective study. IP Journal of Diagnostic Pathology and Oncology. 2018 Jun 15;3(2):91-5.

14. Malik A, Siraj F, Shruti S, Gupta P, Khullar G, Ramesh V. Clinicopathological Concordance in 2216 Cases of Skin Biopsy over One Year: An Indian Experience. Cureus. 2020 Apr;12(4).

15. Balasubramanian P, Chandrashekar L, Thappa DM, Jaisankar TJ, Malathi M, Ganesh RN, Singh N. A retrospective audit of skin biopsies done in a tertiary care center in India. International journal of dermatology. 2015 Aug; 54(8):939-43.

16. George VP, Sowmya S, Krishnan S. A histopathological study of skin biopsy specimens in a tertiary care hospital with a keynote on clinicopathological correlation. Annals of Pathology and Laboratory Medicine. 2020 January; 7 (1): $39-45$. 